\title{
The Effects of Care Team Roles on Situation Awareness in the Pediatric Intensive Care Unit: A Prospective Cross-Sectional Study
}

\author{
Blaise T Soberano1, Patrick Brady, MD, MSc ${ }^{2,3}$, Toni Yunger ${ }^{1}$, Rhonda Jones, BSN ${ }^{1}$, Erin Stoneman ${ }^{1}$, Tina Sosa, MD $^{3}$, \\ Erika L Stalets, MD, MS ${ }^{1,2}$, Matthew Zackoff, MD, MEd ${ }^{1,2}$, Ranjit Chima, MD ${ }^{1,2}$, Ken Tegtmeyer, MD ${ }^{1,2}$, Maya Dewan, MD, MPH¹,24* \\ ${ }^{1}$ Division of Critical Care Medicine, Cincinnati Children's Hospital Medical Center, Cincinnati, Ohio; ${ }^{2}$ Department of Pediatrics, University of Cin- \\ cinnati College of Medicine, Cincinnati, Ohio; ${ }^{3}$ Division of Hospital Medicine, Cincinnati Children's Hospital Medical Center, Cincinnati, Ohio; \\ ${ }^{4}$ Division of Biomedical Informatics, Cincinnati Children's Hospital Medical Center, Cincinnati, Ohio.
}

Improved situation awareness (SA) decreases rates of clinical deterioration in the pediatric inpatient setting. We used a prospective, cross-sectional, observational study to measure interprofessional care team SA for a pediatric intensive care unit (PICU) patients. The resident, bedside nurse, and respiratory therapist for each patient were surveyed regarding high clinical deterioration risk status as defined by clinical criteria identified by the PICU fellow or attending and mitigation plan. From March 2018 to July 2019, we surveyed 400 care team trios caring for 73 high-risk patients. Nurses identified the patient's risk status correctly for 375 of 400 patients (94\%), respiratory therapists, $380(95 \% ; P=.4)$, and residents, 349 (87\%; $P=.002)$. For the 73 high-risk patients, nurses were correct $82 \%$ of the time, respiratory therapists, $85 \%, P=.7$, and residents, $67 \%, P=.04$. Interventions targeting resident SA are needed within the PICU, especially for high-risk patients. Journal of Hospital Medicine 2020;15:594-597. (c) 2020 Society of Hospital Medicine
Reduction in serious pediatric medical errors has been achieved through sharing of best practices and structured collaboration. ${ }^{1}$ However, limited progress has been made in reducing complex, multifactorial events such as unrecognized and undertreated patient deterioration events. ${ }^{2}$ To address this critical gap, interventions to improve clinician situation awareness (SA) have increasingly been applied. ${ }^{3}$

SA is the ability to recognize and monitor cues regarding what is happening, create a comprehensive picture with available information, and extrapolate whether it indicates adverse developments either immediately or in the near future. ${ }^{4}$ Methods such as care team huddling ${ }^{5-8}$ and using standardized patient acuity scoring instruments ${ }^{9}$ increase SA shared across care team roles. Shared SA is the degree to which each team member possesses a common understanding of what is going on. A team is considered to have shared SA when all the individuals agree on both what is happening (accurate perception and comprehension) and what is going to happen in the future (correct projection). Shared SA for high-risk patients in the pediatric intensive care unit (PICU) has not previously been described and may be an opportunity to improve interprofessional team communication for the sickest patients. Shared SA for high-risk patient status is only one aspect of SA, but it fa-

*Corresponding Author: Maya Dewan, MD, MPH; Email: maya.dewan@cchmc. org; Telephone: 215-756-7060; Twitter: @mommimaya.

Published online first August 19, 2020.

Find additional supporting information in the online version of this article.

Received: January 29, 2020; Revised: March 31, 2020; Accepted: April 17, 2020

(c) 2020 Society of Hospital Medicine DOI 10.12788/jhm.3449 cilitates team-based mitigation planning and is an important starting place for understanding opportunities to improve SA. The primary objective of this study was to measure and compare SA among care team roles regarding patients with highrisk status in the PICU.

\section{METHODS}

We conducted a prospective, cross-sectional study from March 2018 to July 2019 examining the individual and shared SA of patient care team trios: the nurse, respiratory therapist (RT), and pediatric resident. The Institutional Review Board at Cincinnati Children's Hospital Medical Center (CCHMC) determined this study to be non-human-subjects research.

\section{Setting}

Research was conducted in the 35-bed PICU of CCHMC, a 500-bed academic free-standing quaternary care children's hospital.

\section{Participants}

We conducted independent surveys of the nurse, RT, and pediatric resident (care team trio) caring for each patient regarding the patient's clinical deterioration risk status. No patients or care team trios were excluded.

\section{Reference Standard}

In 2016, a local panel of experts derived clinical criteria to determine high-risk status for PICU patients, the definition of which, as well as other study terms, appears in Table 1. A PICU attending or fellow identifies a patient as "high risk" when these clinical criteria are met. A plan for prevention and mitigation 
TABLE 1. Key Terminology

\begin{tabular}{|c|c|}
\hline Term & Definition \\
\hline High-Risk Patient & $\begin{array}{l}\text { Patient meets one or more of the following as identified by PICU attending/fellow: on ECMO or at risk of placement on ECMO, risk of a code event or recent code event, at risk } \\
\text { for intubation, at risk of hypotension, or other risk for acute deterioration (including anaphylaxis or arrhythmia). }\end{array}$ \\
\hline $\begin{array}{l}\text { Prevention and } \\
\text { Mitigation Plan }\end{array}$ & $\begin{array}{l}\text { Plan formulated for high-risk patients by PICU attending/fellow that includes prevention of and response to potential deterioration. This is shared during shift huddle. } \\
\text { For example, "Initiate norepinephrine at } 0.03 \mu \mathrm{g} / \mathrm{kg} \text { per minute if mean arterial pressure is }<55 \mathrm{~mm} \mathrm{Hg."}\end{array}$ \\
\hline Care Team Trios & Patient's care team comprising the bedside nurse, the RT for the PICU pod (five to nine rooms clustered within a specific area), and the on-call resident. \\
\hline Reference Standard & Identification of high-risk patient status and development of the prevention and mitigation plan as completed by the PICU fellow or attending. \\
\hline $\begin{array}{l}\text { Shared Situation } \\
\text { Awareness }\end{array}$ & $\begin{array}{l}\text { The degree to which each team member possesses a common understanding of the situation. A team can be considered to have high shared situation awareness when all of } \\
\text { the individuals agree. }\end{array}$ \\
\hline Situation Awareness & The perception of elements in the environment, comprehension of their meaning, and prediction of their status in the near future. \\
\hline $\begin{array}{l}\text { Situation Awareness } \\
\text { Huddles }\end{array}$ & $\begin{array}{l}\text { Brief, structured discussions aiming to identify and discuss unit safety concerns. Attended by supervisory clinicians, charge RN, and charge RT only. The fellow and charge RN } \\
\text { are responsible for sharing information discussed with the bedside staff. These huddles occurred at approximately } 11 \text { AM and } 11 \text { PM daily. Surveys were conducted following the } \\
\text { huddles prior to the end of the shift. }\end{array}$ \\
\hline
\end{tabular}

Abbreviations: ECMO, extracorporeal membrane oxygenation; PICU, pediatric intensive care unit; RN, registered nurse; RT, respiratory therapist.

TABLE 2. Team Situation Awareness With Total N by Care Provider Role

\begin{tabular}{|c|c|c|c|}
\hline Role, \% (n/N) & Bedside nurses & Respiratory therapists & Residents \\
\hline Correct Overall Patient Risk-Status Identification ( $N=400)$ & $94 \%(375 / 400)$ & $95 \%(380 / 400)$ & $87 \%(349 / 400)$ \\
\hline Correct Patient Risk-Status Identification for High-Risk Patients Only ( $N=73$ ) & $82 \%(60 / 73)$ & $85 \%(62 / 73)$ & $67 \%(49 / 73)$ \\
\hline Presence of Mitigation Plan Correctly Identified (N Based on Correct Patient Risk-Status Identification) & $98 \%(59 / 60)$ & $90 \%(56 / 62)$ & $88 \%(43 / 49)$ \\
\hline Content of Mitigation Plan Correctly Identified (N Based on Presence of Mitigation Plan Accurately Identified) & $83 \%(49 / 59)$ & $68 \%(38 / 56)$ & $70 \%(30 / 43)$ \\
\hline
\end{tabular}

is formulated and documented for high-risk patients by the PICU attending or fellow at two preexisting daily SA huddles. This plan includes prevention measures to take immediately, specific vital sign thresholds for early identification of deterioration, and guidance on which emergency medication order sets should be utilized to expedite treatment in the event of clinical decline. Dissemination of the care team's plan is the responsibility of the PICU fellow with additional follow-up by the charge nurse to improve reliability. Identification of highrisk status and development of the prevention and mitigation plan, as completed by the PICU fellow or attending, served as the reference standard for this study.

\section{Survey Instrument Development}

The locally developed survey tool was modeled after a validated handoff communication instrument. ${ }^{10}$ The tool covered the patient's risk status, which high-risk clinical criteria were met, the presence and content of a mitigation plan, and planned patient interventions (Appendix).

\section{Data Collection}

Care team trios were sampled weekly on weekdays during day and night shifts within 4 to 6 hours of the SA huddle by a core group of three research assistants. Care team trios for one group of five to nine patients within a small geographically isolated pod were surveyed each time. The care team trio was surveyed individually regarding the patient's risk status, the high-risk clinical criteria met, the presence and content of a mitigation plan, and planned patient interventions. The responses were compared for accuracy against the reference standard, which was defined as identification of high-risk patient status and development of the prevention and mitigation plan as completed by the PICU fellow or attending.

\section{Data Analysis}

Rates of agreement between the reference standard and individual members of the care team trio were evaluated via a calculation of proportions by care team role. The agreement between each care team trio member and the reference standard was compared with the nurse role performance using chisquare tests. Rates of concordance within the members of the care team trio were calculated via Light's kappa for determination of high-risk status. ${ }^{11}$ Assuming a correct assessment of highrisk status of $62 \%,{ }^{12}$ with a difference between groups of $10 \%$, a sample size of 400 bedside provider trios gives a power of $85 \%$ at the $P<.05$ significance level for a two-sided chi-square test.

\section{RESULTS}

Between March 1, 2018, and July 11, 2019, 400 care team trios were surveyed. Seventy-three trios cared for patients designat- 


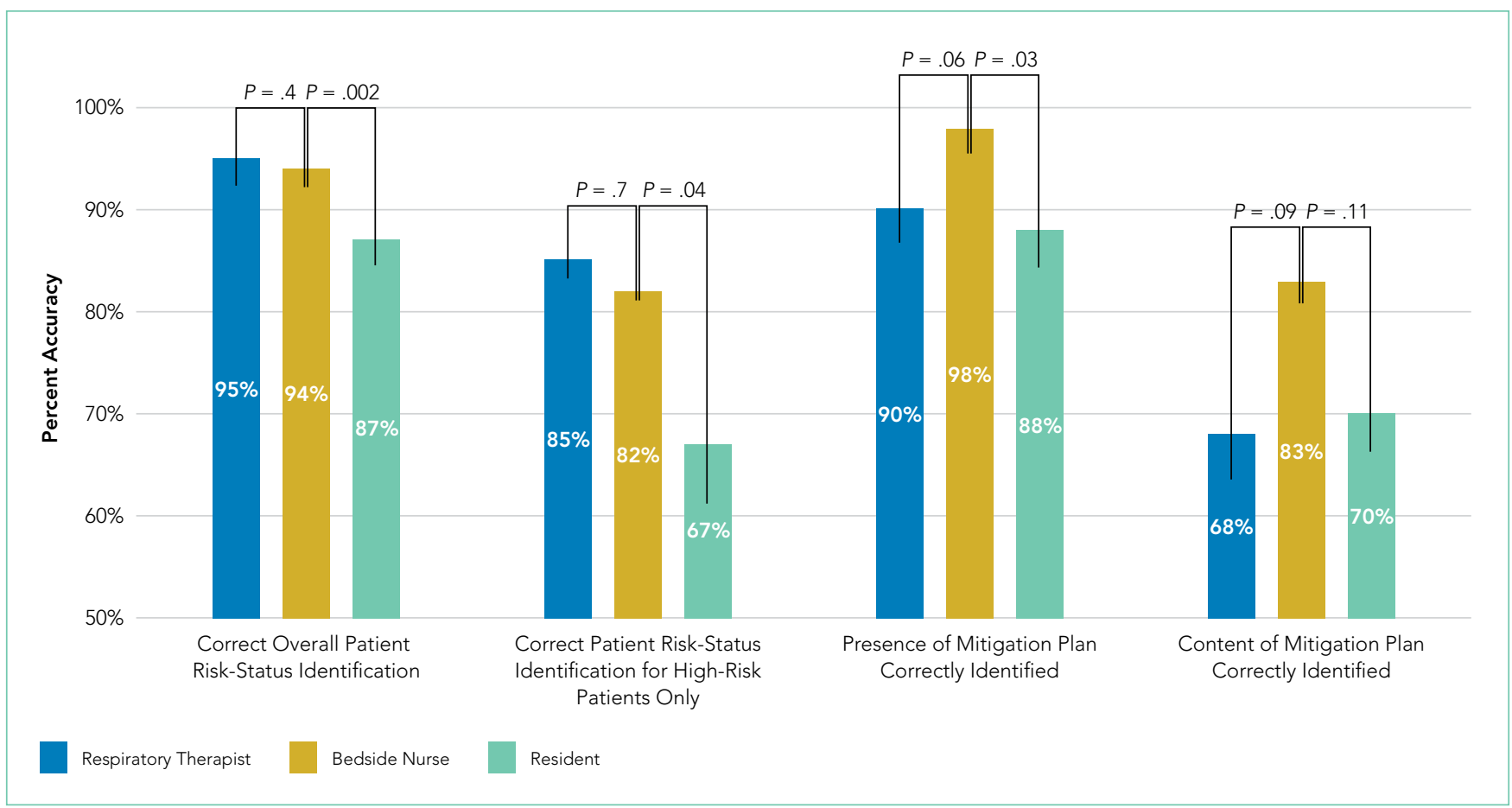

FIG. Components of Shared Situation Awareness by Care Team Role

ed high risk (Table 2 for $\mathrm{N}$ and proportions). Among all surveyed trios, $94 \%$ of nurses (reference), $95 \%$ of RTs $(P=.4$ ), and $87 \%$ of residents $(P=.002)$ identified patient's risk status correctly. Care trio member concordance for high-risk status was moderate agreement as assessed by a kappa of 0.57 (95\% Cl, 0.25-0.90).

Of the 73 high-risk patients, nurses correctly identified risk status for $82 \%$ (reference), RTs $85 \%(P=.7)$, and residents $67 \%$ $(P=.04)$. For high-risk patients, nurses identified the presence of a mitigation plan for $98 \%$ of patients (reference), RTs $90 \%$ $(P=.06)$, and residents $88 \%(P=.03)$. Among the care team members who correctly identified the presence of a mitigation plan, nurses were able to specify the correct plan for $83 \%$ of patients (reference), RTs for 68\% $(P=.09)$, and residents for $70 \%(P=.11$; Figure).

When shared SA for high-risk patients was examined more closely, all three care team roles correctly identified the clinical reason for high-risk status for $32 \%$ of patients, with only one or two clinicians being correct for $53 \%$. All three care team clinicians were incorrect for $15 \%$ of high-risk patients. Among trios with partial accuracy in which two of three care team members correctly identified a patient as high risk, we examined which care-member was most likely to be incorrect. Nurses incorrectly identified risk for $17 \%$ of patients (reference), RTs $19 \%$ $(P=.8)$, and residents 64\% $(P<.0001)$.

\section{DISCUSSION}

Examining 400 care team trios, we found lower individual SA for residents, compared with nurses, regarding high-risk status, the reason for this status, and the presence of a mitigation plan. In all reported measures except for the content of mitigation plans, residents were significantly less correct than the bedside nurses while RTs performed similarly to bedside nurses throughout. In addition, there was only moderate agreement between care team roles, which shows further opportunities for improvement in shared SA. The disparities between care team roles are consistent with studies that suggest certain factors grounded in institutional culture and interpersonal dynamics, such as poor communication, can lead to breakdowns in shared knowledge. ${ }^{13,14}$ Communication issues demonstrate differences across care team roles ${ }^{14}$ and may provide insight into barriers to individual and shared SA throughout the care team.

In addition, the effects of patient load on SA needs further study. While our PICU nurses are commonly assigned to 1 to 2 patients, RTs care for 7 to 11 patients, and an on-call resident may be covering 15 to 20 patients during a high-census season. The increased patient load cannot serve as an excuse for the knowledge gap regarding high-risk status and mitigation plan, but may provide an opportunity to support residents and other medical providers through the use of clinical decisionsupport tools that indicate high-risk status and represent mitigation plans. ${ }^{12}$

This study has multiple limitations. First, while we based our survey tool on a communication assessment tool with prior validity evidence, ${ }^{10,12}$ our tool has not been used prior to this study. The adapted tool contained relevant categorizations of patient information, including explicit statement of patient status and planned treatment consistent with study definitions of SA, and has been used in the critical care setting previously. ${ }^{11}$ The survey tool used to measure SA in this study was locally designed and implemented only within the study unit, which could lead to decreased reliability and generalizability of the results to other units and institutions at large. Second, while 
the sample size for the primary measure $(N=400)$ was adequately powered because our baseline SA was higher than estimated, we had insufficient power for some subgroup analyses that can lead to type II errors. Third, care team trios may have been surveyed repeatedly on the same patient without adjustment in the results for repeated measures. However, as we surveyed on average only once a week and alternated areas of the PICU surveyed, it is unlikely that it affected results given that the most lengths of stay within the PICU range from 3 to 4 days. Finally, individual characteristics of patients were not collected for this work, and therefore, no adjustments or further analysis can be made on the effect of the patient characteristic on the care team role SA.

\section{CONCLUSION}

This study is the first to assess differences in individual and shared SA within a PICU by care team role. Efforts to expand on these findings should include investigation into the causes for the disparities in SA among care team roles for individual patients and among the care teams of high-risk and normal-risk patients. Given the association between increased SA and improved patient outcomes, ${ }^{4}$ future efforts should be structured to address care team role-specific gaps in SA because these may advance the quality of care in the pediatric inpatient setting.

Disclosures: Dr Brady has a grant from the Agency for Healthcare Research and Quality (K08HS023827) payable to his institution. The other authors have nothing to disclose.

\section{References}

1. Lyren A, Brilli RJ, Zieker K, Marino M, Muething S, Sharek PJ. Children's hospitals' solutions for patient safety collaborative impact on hospital-acquired harm. Pediatrics. 2017;140(3):e20163494. https://doi.org/10.1542/peds.20163494

2. Buist $M$, Bernard $S$, Nguyen TV, Moore G, Anderson J. Association between clinically abnormal observations and subsequent in-hospital mortality: a prospective study. Resuscitation. 2004;62(2):137-141. https://doi.org/10.1016/j. resuscitation.2004.03.005

3. Brady PW, Muething S, Kotagal U, et al. Improving situation awareness to reduce unrecognized clinical deterioration and serious safety events. Pediatrics. 2013;131(1):e298-308. https://doi.org/10.1542/peds.2012-1364

4. Endsley MR. Theoretical underpinnings of situation awareness: a critical review. In: Endsley MR, Garland DJ, eds. Situation Awareness Analysis and Measurement. Lawrence Erlbaum Associates; 2000.

5. Dewan $\mathrm{M}$, Wolfe $\mathrm{H}$, Lin $\mathrm{R}$, et al. Impact of a safety huddle-based intervention on monitor alarm rates in low-acuity pediatric intensive care unit patients. $J$ Hosp Med. 2017;12(8):652-657. https://doi.org/10.12788/jhm.2782

6. Bonafide $C P$, Localio $A R$, Stemler $S$, et al. Safety huddle intervention for reducing physiologic monitor alarms: a hybrid effectiveness-implementation cluster randomized trial. J Hosp Med. 2018;13(9):609-615. https://doi. org/10.12788/jhm.2956

7. Provost SM, Lanham HJ, Leykum LK, McDaniel RR Jr, Pugh J. Health care huddles: managing complexity to achieve high reliability. Health Care Manage Rev. 2015;40(1):2-12. https://doi.org/10.1097/HMR.0000000000000009

8. Goldenhar LM, Brady PW, Sutcliffe KM, Muething SE, Anderson JM. Huddling for high reliability and situation awareness. BMJ Qual Saf. 2013;22(11):899906. https://doi.org/10.1136/bmjgs-2012-001467

9. Edelson DP, Retzer E, Weidman EK, et al. Patient acuity rating: quantifying clinical judgment regarding inpatient stability. J Hosp Med. 2011;6(8):475479. https://doi.org/10.1002/jhm.886

10. Shahian DM, McEachern K, Rossi L, Chisari RG, Mort E. Large-scale implementation of the I-PASS handover system at an academic medical centre. BMJ Qual Saf. 2017;26(9):760-770. https://doi.org/10.1136/bmjqs-2016-006195

11. Gamer M, Lemon J, Fellows I, Singh P. Various Coefficients of Interrater Reliability and Agreement. January 26, 2019. Accessed January 24, 2020. http:// cran.r-project.org/web/packages/irr/irr.pdf

12. Shelov E, Muthu N, Wolfe H, et al. Design and implementation of a pediatric ICU acuity scoring tool as clinical decision support. Appl Clin Inf. 2018;09(3):576-587. https://doi.org/10.1055/s-0038-1667122

13. Sutcliffe KM, Lewton $E$, Rosenthal MM. Communication failures: an insidious contributor to medical mishaps. Acad Med. 2004;79(2):186-194. https://doi. org/10.1097/00001888-200402000-00019

14. Sexton B, Thomas E, Helmreich RL. Error, stress, and teamwork in medicine and aviation: cross sectional surveys. BMJ. 2000;320(7237):745-749. doi:10.1136/bmj.320.7237.745 